\title{
Stable and robust control strategy using interval-valued fuzzy systems
}

\author{
Nadia Bounouara ${ }^{1}$, Mouna Ghanai ${ }^{2}$, Ali Medjghou ${ }^{3}$, Kheireddine Chafaa ${ }^{4}$ \\ ${ }^{1,2,4}$ LAAAS Laboratory, Department of Electronics, Mostefa Benboulaid; Batna 2 University, Algeria \\ ${ }^{3}$ LI3cub Laboratory, Electrical Engineering Department, University of Biskra, Algeria
}

\section{Article Info \\ Article history: \\ Received Apr 18, 2019 \\ Revised Feb 19, 2020 \\ Accepted Apr 15, 2020}

\section{Keywords:}

Fuzzy adaptive control Induction motor Interval valued membership Type reduction Type-2 fuzzy systems

Vector control

\section{Corresponding Author:}

Nadia Bounouara, Department of Electronics, Mostefa Ben Boulaid; Batna 2 University, Avenue Chahid Boukhlouf 05000 Batna, Algeria.

Email: n.bounouara@univ-batna2.dz

\begin{abstract}
In this paper we propose an adaptive interval valued fuzzy controller for high performance direct vector-controlled induction motor drive. Interval valued controller compared with type-1 fuzzy controller has the advantage that it can take into account the linguistic uncertainties present in the rules of the estimated models. The proposed control framework consists of a mixture of two controllers: an interval valued fuzzy controller and a supervisory controller. The supervisory controller is used when the system starts to become unstable. The free parameters for the proposed controller are changed according to some learning rules based on Lyapunov stability. Simulation results on an induction motor show the effectiveness of the introduced method.
\end{abstract}

This is an open access article under the CC BY-SA license.

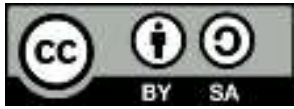

\section{INTRODUCTION}

Induction motor (IM) has been broadly used in industrial applications due to its advantages such as its simple construction, reliability, efficiency, low cost and possibility to operate in aggressive environment. However, It is difficult to control it due to (1) its nonlinear dynamics (2) electric rotor variables are not measurable and (3) physical parameters are often imprecisely known (can change with time) [1,2]. Many schemes have been proposed for the control of induction motor drives, among which the direct field oriented control (DFOC) has been accepted as one of the most effective methods [1,3]. In the conventional DFOC, PI regulators are used to control the flux magnitude and rotor speed. It is well known that standard regulators with fixed parameters may be insufficient to achieve good static and dynamic performance when the induction motor drives systems are subjected to large variation of inertia during their normal operating cycles [4]. In this case, more sophisticated controllers are required such as fuzzy controllers which are very useful when the controlled plant have some uncertainties or unknown variations.

In the past decade, fuzzy logic control (FLC) strategy has been the focus of many studies and research for the control of nonlinear systems [5-8]. One of the advantages of the fuzzy based control is that linguistic information can be directly incorporated into the controller without need an accurate mathematical model of the plant. Though, in presence of parameters variation of the plant, recourse to adaptive control is in most cases unavoidable. Adaptive fuzzy concept combines the robustness of fuzzy logic systems and the adaptation capabilities of adaptive control. Adaptive fuzzy controllers (AFC) provided an attracting approach to obtain the fuzzy parameters of a FLC by using a tuning algorithm. Model reference adaptive fuzzy control (MRAFC) technique has been applied usefully to control induction motor drives [9-11]. 
Type-2 fuzzy logic is an extension of type-1 fuzzy logic; it was introduced by Jerry M. Mendel [12] as an efficient tool which can outperform type-1 fuzzy logic in many situations, especially when uncertainties are present. Type-2 fuzzy logic was applied in many engineering areas, and the first application in adaptive control was proposed in $[13,14]$ where the authors gave how a type-2 fuzzy system can be used as a control system. Two approaches may be considered to reduce the computational burden while preserving the performance and the advantages of a type-2 fuzzy system: 1) Using a faster type-reduction method. Several algorithms are being developed for this purpose, including the modified enhanced Karnik-Mendel (MEKM) method [15], enhanced Karnik-Mendel (EKM) method, the enhanced iterative algorithm with stop condition (EIASC) method and many other methods reported in [16]. 2) Using a simple architecture with a reduced number of membership functions and rules.

This paper develops a new indirect adaptive type-2 fuzzy controller (IAFC) for induction motors based on MEKM algorithm. The proposed scheme is based on the use of two controllers, the first one determines the feedback control by using type-2 fuzzy logic systems, and the second one generates the supervisory control (SC) action to stabilize the whole system when it tend to be unstable. The rest of the paper is organized as follows. Section 2 describes briefly induction motor model and its vector control. Problem formulation is given in section 3. In section 4 we propose the design of the type-2 fuzzy logic controller. Parameters adaptation is described in section 5. Application to an induction motor and simulation results are presented in section 6 . Finally, the conclusion is given in section 7 .

\section{INDUCTION MOTOR AND VECTOR CONTROL}

The dynamic behaviour of an induction machine in $d q$ synchronous reference is described by:

$$
\begin{aligned}
& \frac{d i_{d s}}{d t}=\frac{1}{\sigma L_{s}}\left(-\left(R_{s}+\left(\frac{L_{m}}{L_{r}}\right)^{2} R_{r}\right) i_{d s}+\sigma L_{s} \omega_{s} i_{q s}+\frac{L_{m} R_{r}}{L_{r}^{2}} \phi_{d r}+\frac{L_{m}}{L_{r}} \phi_{q r} \omega_{r}+u_{d s}\right) \\
& \frac{d i_{q s}}{d t}=\frac{1}{\sigma L_{s}}\left(-\sigma L_{s} \omega_{s} i_{d s}-\left(R_{s}+\left(\frac{L_{m}}{L_{r}}\right)^{2} R_{r}\right) i_{q s}-\frac{L_{m}}{L_{r}} \phi_{d r} \omega_{r}+\frac{L_{m} R_{r}}{L_{r}^{2}} \phi_{q r}+u_{q s}\right) \\
& \frac{d \phi_{d r}}{d t}=\frac{L_{m}}{T_{r}} i_{d s}-\frac{\phi_{d r}}{T_{r}}+\left(\omega_{s}-\omega_{r}\right) \phi_{q r} \\
& \frac{d \phi_{q r}}{d t}=\frac{L_{m}}{T_{r}} i_{q s}-\frac{\phi_{q r}}{T_{r}}-\left(\omega_{s}-\omega_{r}\right) \phi_{d r} \\
& \frac{d \omega_{r}}{d t}=\frac{p}{J} T_{e}-\frac{B}{J} \omega_{r}-\frac{p}{J} T_{L}
\end{aligned}
$$

where $u_{d s}, u_{q s}$ are $d$ - and $q$-axis stator voltages; $i_{d s}, i_{q \text { s }}$ are $d$ - and $q$-axis stator currents; $\phi_{d r}, \phi_{q r}$ are $d$ - and $q$-axis rotor flux linkages; $\omega_{s}, \omega_{r}$ are stator angular frequency and rotor electrical angular speed; $R_{s}, R_{r}$ are stator and rotor resistances; $L_{s}, L_{r}$ and $L_{m}$ are stator inductance, rotor inductance and mutual inductance; $T_{r}=L_{r} / R_{r}$ is the rotor time constant; $\sigma$ is the total leakage factor $\sigma=1-L_{m}^{2} /\left(L_{s} L_{r}\right) ; T_{e}, T_{L}$ are electromagnetic torque and load torque; $p$ is the number of poles; $J$ is the inertial moment of the motor; and $B$ is viscous friction coefficient. The produced electromagnetic torque can be written in terms of stator currents and rotor fluxes as:

$$
T_{e}=\frac{p L_{m}}{L_{r}}\left(i_{q s} \phi_{d r}-i_{d s} \phi_{q r}\right)
$$

The decoupling control of torque and rotor flux can be obtained using the vector control technique $[1,3]$. In the rotor flux oriented vector, the flux is oriented to the $\mathrm{d}$ axis, so that $\phi_{q r}=0$, and kept at a constant rated value $\phi_{d r}=\phi_{r}$. At steady-state, slip angular frequency can be expressed as:

$$
\omega_{s l}=\omega_{s}-\omega_{r}=\frac{L_{m} R_{r} i_{q s}}{L_{r} \phi_{r}}
$$

the generated motor torque $T_{e}(6)$ is reduced to a linear function of the torque current component $i_{q s}$ : 


$$
T_{e}=\frac{p L_{m} \phi_{r}}{L_{r}} i_{q s}
$$

the application of vector control in the current model of IM leads to the following equations:

$$
\begin{aligned}
& \frac{d \phi_{r}}{d t}=-\frac{\phi_{r}}{T_{r}}+\frac{L_{m}}{T_{r}} i_{d s} \\
& \frac{d N}{d t}=-\frac{B}{J} N+\frac{30 p L_{m} \phi_{r}}{\pi J L_{r}} i_{q s}-\frac{30}{\pi J} T_{L}
\end{aligned}
$$

where $\phi_{r}$ is the rotor flux, $N$ is the motor speed expressed in revolution per minute and $\left(i_{d s}, i_{q s}\right)$ are the components of stator current.

\section{PROBLEM FORMULATION}

Consider the first order nonlinear dynamical system of the form:

$$
\left\{\begin{array}{l}
\dot{x}=f(x)+g(x) u+d \\
y=x
\end{array}\right.
$$

by comparing (9) and (10) with (11) we have: For the flux model, $x$ represents the flux $\phi_{r}, f=-\phi_{r} / T_{r}$, $g=L_{m} / T_{r}, u=i_{d s}$, and the external perturbation $d=0$; For the speed model, $x$ represents the speed $N$, $f=-B N / J, g=30 p L_{m} \phi_{r} / \pi J L_{r}, u=i_{q s}$, and $d=-30 T_{L} / \pi J$. Note that the state $\phi_{r}$ is estimated by (9), and we assume that the speed is available for measurement.

The control objective is to find a feedback control law $u$ such that to make the state $x(t)$ track a given desired bounded reference trajectory $y_{m}(t)$.It is known that if the plant model is not known, it is intuitively reasonable to replace it by an estimated model and use this model for designing the controller. This is the basic idea of an indirect adaptive controller, in which the controller is designed based on an estimated model of the plant assuming this model is the true model of the plant, and the estimated model parameters are updated by an on-line algorithm. If the plant dynamics of (11) is known, i.e., $f$ and $g$ are known and the system is free of external disturbance $d$, we can solve the control problem stated above by the so-called feedback linearization method. In this method, $f$ and $g$ are used to construct the following feedback controller:

$$
u=\frac{1}{g(x)}\left[-f(x)+\dot{y}_{m}(t)+k e\right]
$$

where $e=e(t)=y_{m}(t)-y(t)$ is the tracking error, and $k$ is chosen such that the root of the polynomial $h(s)=s+k$ is in the open left-half of the complex plane. Applying the control law given in (12) to the system given in (11) we obtain the following error dynamics:

$$
\dot{e}+k e=0
$$

where the main objective of the control is $\lim _{t \rightarrow \infty} e(t)=0$. However, since $f$ and $g$ are unknown, we cannot use them for constructing the control law given by (12). Therefore, in the following, we replace them by their estimates $\hat{f}$ and $\hat{g}$ to construct an adaptive controller:

$$
u_{c}=u_{c}\left(x / \underline{\theta}_{f}, \underline{\theta}_{g}\right)=\frac{1}{\hat{g}\left(x / \underline{\theta}_{g}\right)}\left[-\hat{f}\left(x / \underline{\theta}_{f}\right)+\dot{y}_{m}(t)+k e\right]
$$

where $\underline{\theta}_{f}$ and $\underline{\theta}_{g}$ are parameters of the approximating systems $\hat{f}$ and $\hat{g}$, respectively. 
Figure 1 shows a bloc diagram of control structure based on IFOC induction motor fed by a currentcontrolled PWM voltage-source inverter. The procedure of hysteresis current control used here consists of a comparison between the current errors against a fixed hysteresis band. The system uses two control loops: flux control and speed control to yield Ids and $I_{q s}$ which represent the controlled flux and torque components respectively. In order to maintain the stator current in acceptable range, the current inputs $\left(I_{d s}, I_{q s}\right)$ are transformed into limited inputs $\left(I_{d s}^{*}, I_{q s}^{*}\right)$. The instantaneous three-phase reference current $\left(i^{*}{ }_{a s}, i_{b s}^{*}, i_{c s}^{*}\right)$ is obtained from the $d q$ stator current $\left(I^{*}{ }_{d s}, I_{q s}^{*}\right)$ by applying the inverse Park transform.

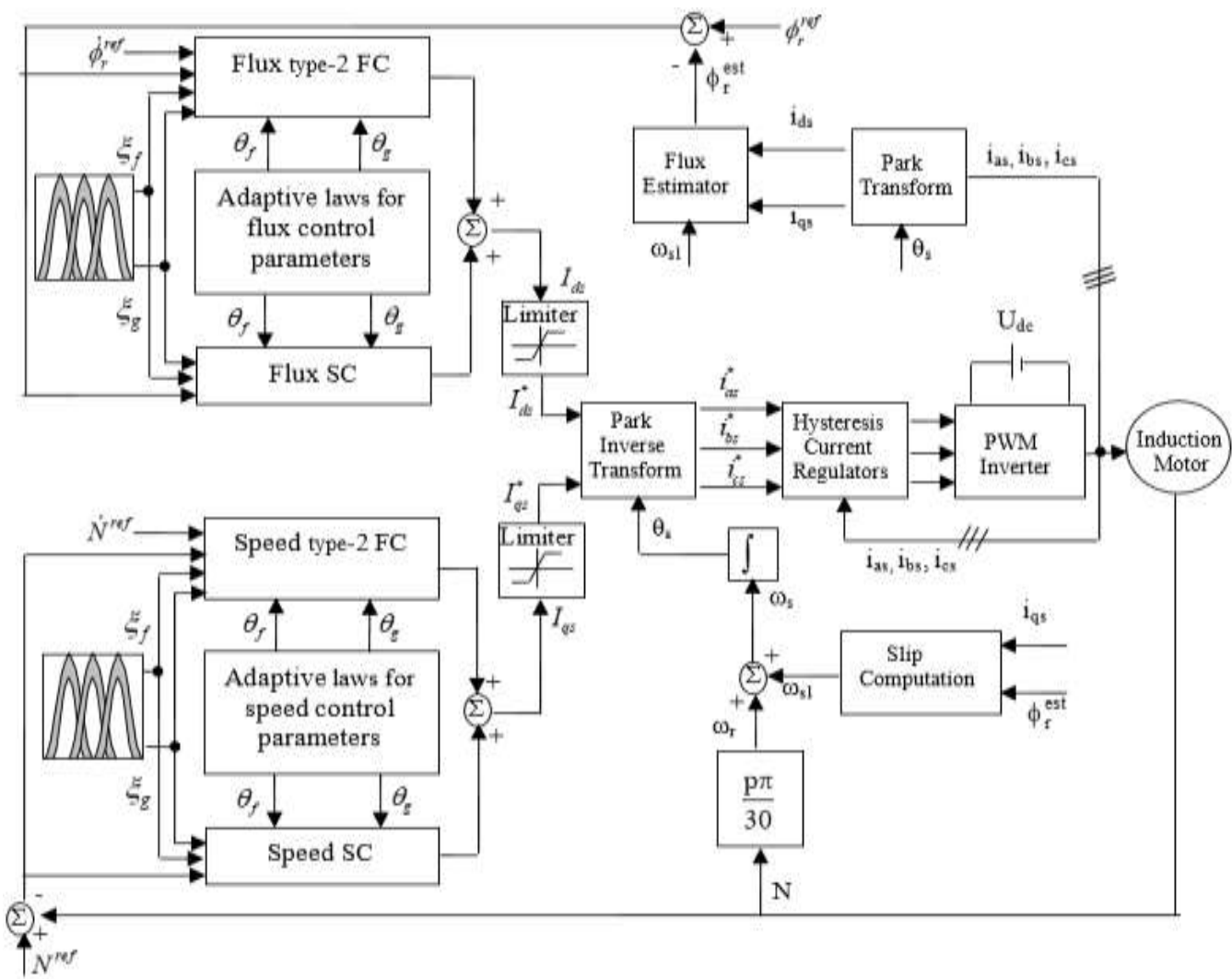

Figure 1. Structure of indirect vector-controlled induction motor drive

\subsection{Type-2 fuzzy logic system design}

Figure 2 depicts the structure of a type-2 FLS; it is quite similar to a type-1 FLS, the only difference being that the antecedent and/or consequent sets in a type-2 FLS are type-2. There are five principal parts in a type-2 FLS: fuzzifier, rule base, inference engine, type-reducer and defuzzifier. The type-2 fuzzy rule base consists of a collection of IF-THEN rules in the following form:

$$
R^{i}: \text { IF } x_{1} \text { is } \tilde{F}_{1}^{i} \text { and ... and } x_{n} \text { is } \tilde{F}_{n}^{i} \text {, THEN } y \text { is } \tilde{G}^{i}
$$

where $\tilde{F}_{j}^{i}$ are antecedent type-2 sets $(j=1,2, \ldots, n), y \in Y$ is the output, $G^{i}$ are consequent type-2 sets, and $i=1,2, \ldots, M$, and $M$ is the total number of rules.

In an interval type-2 FLS with meet under minimum or product t-norm, the firing interval $W^{i}=\left[\underline{w}^{i}, \bar{w}^{i}\right]$ of the $i^{t h}$ rule is an interval type-1 set, which is determined by its left-most and right-most points $\underline{w}^{i}$ and $\bar{w}^{i}$ such that:

$$
\begin{aligned}
& \underline{w}^{i}=\underline{\mu}_{\widehat{F}_{1}^{i}}\left(x_{1}\right) * \cdots * \underline{\mu}_{\hat{F}_{n}^{i}}\left(x_{n}\right) \\
& \bar{w}^{i}=\bar{\mu}_{\widehat{F}_{1}^{i}}\left(x_{1}\right) * \cdots * \bar{\mu}_{\hat{F}_{n}^{i}}\left(x_{n}\right)
\end{aligned}
$$




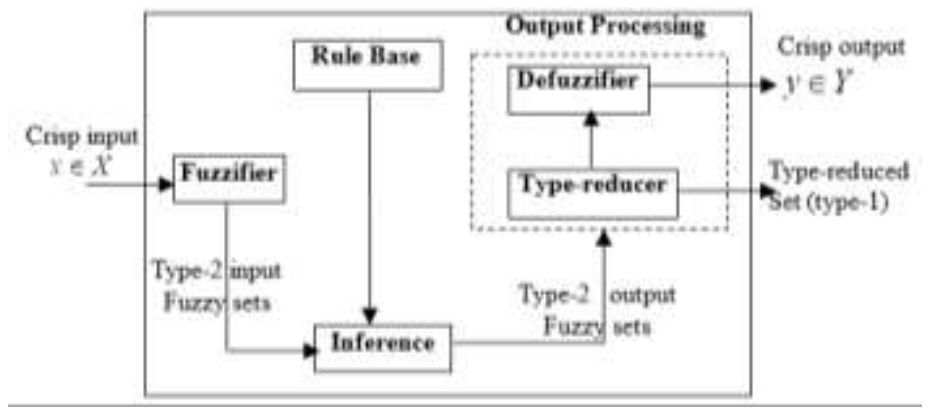

Figure 2. The structure of a type-2 FLS, with its two outputs: type reduced set and crisp defuzzified value

Type reduction was proposed by Karnik and Mendel [17]. It is an extension of type-1 defuzzification method. There exist many kinds of type-reduction [15, 16, 18, 19], and in our work we propose the introduction of MEKM type-reduction method proposed in [17] in the control framework. Let's call centre of sets (cos) the output result of the type reduction process. In this paper, we propose to apply type-2 FLSs to obtain the estimates $\hat{f}$ and $\hat{g}$ for each of flux and speed controllers. The antecedent type-2 membership functions $\mu_{\tilde{F}_{j}^{i}}$ will be fixed as shown in Figure 3, and the consequent sets which are the adjustable parameters will be considered as type- 1 centroids. Since $\hat{f}$ and $\hat{g}$ are type- 2 fuzzy logic systems, their output sets (type-reduced sets) $\tilde{F}_{\text {cos }}$ and $\tilde{G}_{\text {cos }}$ calculated by the centre of sets method will be given as follows:

$$
\begin{aligned}
& \hat{F}_{\cos }\left(\theta_{f}^{1}, \ldots, \theta_{f}^{M}, W_{f}^{1}, \ldots, W_{f}^{M}\right)=\int_{\theta_{f}^{1}} \ldots \int_{\theta_{f}^{M}} \int_{w_{f}^{1}} \ldots \int_{w_{f}^{M}} 1 / \frac{\sum_{i=1}^{M} w_{f}^{i} \theta_{f}^{i}}{\sum_{i=1}^{M} w_{f}^{i}} \\
& \hat{G}_{\cos }\left(\theta_{g}^{1}, \ldots, \theta_{g}^{M}, W_{g}^{1}, \ldots, W_{g}^{M}\right)=\int_{\theta_{g}^{1}} \ldots \int_{\theta_{g}^{M}} \int_{w_{g}^{1}} \ldots \int_{w_{g}^{M}} 1 / \frac{\sum_{i=1}^{M} w_{g}^{i} \theta_{g}^{i}}{\sum_{i=1}^{M} w_{g}^{i}}
\end{aligned}
$$

where $w_{f}^{i}$ and $w_{g}^{i}$ are the firing intervals corresponding to the $i^{\text {th }}$ rule of the type-2 FSs $\hat{f}$ and $\hat{g}$, respectively, $\underline{\theta}_{f}^{i}$ and $\underline{\theta}_{g}^{i}$ are the free parameters of the type-2 FSs $\hat{f}$ and $\hat{g}$, respectively. Since each set on the right-hand side of (18) and (19) is an interval type-1 set, hence $\hat{F}_{\text {cos }}$ and $\hat{G}_{\text {cos }}$ are also an interval type-1 sets. So, to find $\hat{F}_{\text {cos }}$ and $\hat{G}_{\text {cos }}$, we just need to compute the two end points of these intervals.
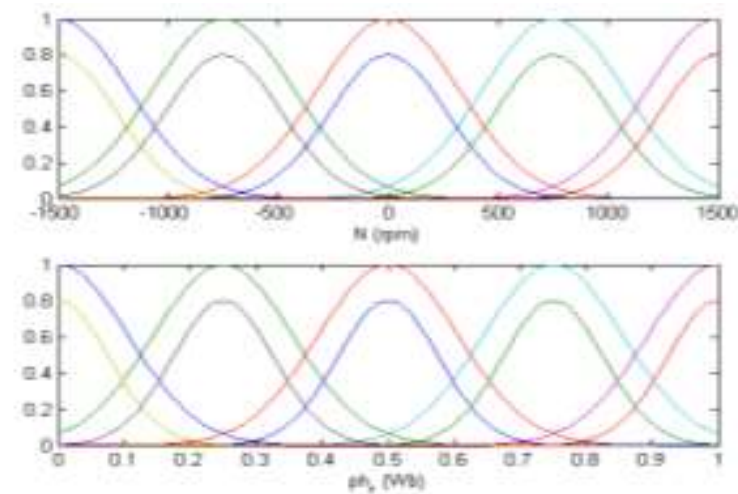

Figure 3. Antecedent type-2 membership functions 
In [20-23] only one type-1 vector of fuzzy basis functions $\underline{\xi}(\underline{x})$ was used to obtain $\hat{f}$ and $\hat{g}$ simultaneously. Unfortunately, this does not carry over to type-2 FLSs, due to that type-reduction will give for each $\hat{f}$ and $\hat{g}$ two different vectors of fuzzy basis functions. Next we will show how type-2 fuzzy logic will associate with every $\hat{f}$ and $\hat{g}$ a self vector of fuzzy basis functions $\xi_{f}(x)$ and $\xi_{g}(x)$, respectively. For any value of $\hat{f} \in \hat{F}_{\text {cos }}$ and for any value of $\hat{g} \in \hat{G}_{\text {cos }}, \hat{f}$ and $\hat{g}$ can be represented as:

$$
\hat{f}=\frac{\sum_{i=1}^{M} w_{f}^{i} \theta_{f}^{i}}{\sum_{i=1}^{M} w_{f}^{i}}, \hat{g}=\frac{\sum_{i=1}^{M} w_{g}^{i} \theta_{g}^{i}}{\sum_{i=1}^{M} w_{g}^{i}}
$$

respectively. The maximum values of $\hat{f}$ and $\hat{g}$ are $\hat{f}_{r}$ and $\hat{g}_{r}$ respectively, and the minimum values of $\hat{f}$ and $\hat{g}$ are $\hat{f}_{l}$ and $\hat{g}_{l}$ respectively. In the centre of sets (cos)-type reduction method Karnik and Mendel [18] have shown that the two end points of $\hat{F}_{\text {cos }}, \hat{f}_{l}$ and $\hat{f}_{r}$ depend only on a mixture of $\underline{w}_{f}^{i}$ or $\bar{w}_{f}^{i}$ values, since $w_{f}^{i} \in\left[\underline{w}_{f}^{i}, \bar{w}_{f}^{i}\right]$. In the same manner, the two end points of $\hat{G}_{\text {cos }}, \hat{g}_{l}$ and $\hat{g}_{r}$ depend only on a mixture of $\underline{w}_{g}^{i}$ or $\bar{w}_{g}^{i}$ values, since $w_{g}^{i} \in\left[\underline{w}_{g}^{i}, \bar{w}_{g}^{i}\right]$. In this case, $\hat{f}_{l}, \hat{f}_{r}, \hat{g}_{l}$ and $\hat{g}_{r}$ can each be represented as a vector of fuzzy basis functions (FBF) expansion, i.e.,

$$
\hat{f}_{l}=\frac{\sum_{i=1}^{M} w_{f l}^{i} \theta_{f}^{i}}{\sum_{i=1}^{M} w_{f l}^{i}}=\sum_{i=1}^{M} \theta_{f}^{i} \xi_{f l}^{i}=\underline{\theta}_{f}^{T} \underline{\xi}_{f l}(\underline{x})
$$

where $w_{f l}^{i}$ is the firing strength membership (either $\underline{w}_{f}^{i}$ or $\bar{w}_{f}^{i}$ ) contributing to the left-most point $\hat{f}_{l}$, s.t:

$$
\xi_{f l}^{i}=\frac{w_{f l}^{i}}{\sum_{i=1}^{M} w_{f l}^{i}}
$$

are the components of the first FBF vector $\underline{\xi}_{f l}(\underline{x})$ of $\hat{f}$, i.e., $\underline{\xi}_{f l}^{T}(\underline{x})=\left[\xi_{f l}^{1}, \ldots, \xi_{f l}^{M}\right]$ and $\underline{\theta}_{f}^{T}=\left[\theta_{f}^{1}, \ldots, \theta_{f}^{M}\right]$ is the parameter vector of the type-2 FLS $\hat{f}$. Similarly,

$$
\hat{f}_{r}=\frac{\sum_{i=1}^{M} w_{f r}^{i} \theta_{f}^{i}}{\sum_{i=1}^{M} w_{f r}^{i}}=\sum_{i=1}^{M} \theta_{f}^{i} \xi_{f r}^{i}=\underline{\theta}_{f}^{T} \underline{\xi}_{f r}(x)
$$

where $w_{f r}^{i}$ denotes the firing strength membership gradcontributing to the right-most point $\hat{f}_{r}$ and:

$$
\xi_{f r}^{i}=\frac{w_{f r}^{i}}{\sum_{i=1}^{M} w_{f r}^{i}}
$$

are the components of the second FBF vector $\underline{\xi}_{f r}(\underline{x})$ of $\hat{f}$, i.e., $\underline{\xi}_{f r}^{T}(\underline{x})=\left[\xi_{f r}^{1}, \ldots, \xi_{f r}^{M}\right]$. Similarly, we have for $\hat{g}$ two FBF vectors $\underline{\xi}_{g l}^{T}(x)=\left[\xi_{g l}^{1}, \ldots, \xi_{g l}^{M}\right]$ and $\underline{\xi}_{g r}^{T}(x)=\left[\xi_{g r}^{1}, \ldots, \xi_{g r}^{M}\right]$ such that: 


$$
\begin{gathered}
\hat{g}_{l}=\frac{\sum_{i=1}^{M} w_{g l}^{i} \theta_{g}^{i}}{\sum_{i=1}^{M} w_{g l}^{i}}=\sum_{i=1}^{M} \theta_{g}^{i} \xi_{g l}^{i}=\underline{\theta}_{g}^{T} \underline{\xi}_{g l}(x) \\
\hat{g}_{r}=\frac{\sum_{i=1}^{M} w_{g r}^{i} \theta_{g}^{i}}{\sum_{i=1}^{M} w_{g r}^{i}}=\sum_{i=1}^{M} \theta_{g}^{i} \xi_{g r}^{i}=\underline{\theta}_{g}^{T} \underline{\xi}_{g r}(x)
\end{gathered}
$$

where $\underline{\theta}_{g}^{T}=\left[\theta_{g}^{1}, \ldots, \theta_{g}^{M}\right]$ is the parameter vector of the type-2 FLS $\hat{g}$,

$$
\xi_{g l}^{i}=\frac{w_{g l}^{i}}{\sum_{i=1}^{M} w_{g l}^{i}}, \xi_{g r}^{i}=\frac{w_{g r}^{i}}{\sum_{i=1}^{M} w_{g r}^{i}}
$$

To obtain a crisp outputs from the type-2 FLSs $\hat{f}$ and $\hat{g}$, we must defuzzify the type-reduced sets $\hat{F}_{\text {cos }}$ and $\hat{G}_{\text {cos }}$. Since these type reduced sets are interval sets, therefore, the defuzzified output of $\hat{f}$ will be the average of $\hat{f}_{l}$ and $\hat{f}_{r}$, and the defuzzified output of $\hat{g}$ will be the average of $\hat{g}_{l}$ and $\hat{g}_{r}$ i.e.,

$$
\hat{f}=\frac{\hat{f}_{l}+\hat{f}_{r}}{2}, \hat{g}=\frac{\hat{g}_{l}+\hat{g}_{r}}{2}
$$

Replacing (21), (23), (25), and (26) into (28) we obtain:

$$
\begin{aligned}
& \hat{f}=\frac{\underline{\theta}_{f}^{T} \underline{\underline{\xi}_{f}}+\underline{\theta}_{f}^{T} \underline{\xi}_{f r}}{2}=\underline{\theta}_{f}^{T}\left[\frac{\underline{\xi}_{f}+\underline{\xi}_{f r}}{2}\right]=\underline{\theta}_{f}^{T} \underline{\xi}_{f}(\underline{x}) \\
& \hat{g}=\frac{\theta_{g}^{T} \underline{\xi}_{g l}+\underline{\theta}_{g}^{T} \underline{\xi}_{g r}}{2}=\underline{\theta}_{g}^{T}\left[\frac{\underline{\xi}_{g l}+\underline{\xi}_{g r}}{2}\right]=\underline{\theta}_{g}^{T} \underline{\xi}_{g}(\underline{x})
\end{aligned}
$$

where $\underline{\xi}_{f}=\underline{\xi}_{f l}+\underline{\xi}_{f r} / 2$ is the average FBF vector of $\hat{f}$ and $\underline{\xi}_{g}=\underline{\xi}_{g l}+\underline{\xi}_{g r} / 2$ is the average FBF vector of $\hat{g}$. In order to compute $\underline{\xi}_{f l}$ and $\underline{\xi}_{f r}\left(\underline{\xi}_{g l}\right.$ and $\underline{\xi}_{g r}$ ), we need to compute $w_{f l}^{i}$ and $w_{f r}^{i}, i=1,2, \ldots, M$ ( $w_{g l}^{i}$ and $\left.w_{g r}^{i}, i=1,2, \ldots, M\right)$. This can be done using the computational method given in [13-14]. The crisp values of $\hat{f}$ and $\hat{g}$ can be obtained either by (28), or by using the FBFs $\underline{\xi}_{f}(x)$ and $\underline{\xi}_{g}(x)$, respectively, as shown in (29) and (30). Recall that the above method is applied independently to estimate the functions $\hat{f}$ and $\hat{g}$ for both flux and speed models.

\section{PARAMETERS ADAPTATION}

Here, we will develop the IAC-based type-2 fuzzy controller with supervisory control scheme. Applying (14) to (11) and after straightforward manipulation, we obtain the error equation:

$$
e=-k e+\left(\hat{f}\left(x / \underline{\theta}_{f}\right)-f(x)\right)+\left(\hat{g}\left(x / \underline{\theta}_{g}\right)-g(x)\right) u_{c}-d
$$

we know that there exists a unique positive constant $p$ which satisfies the Lyapunov equation:

$$
-k p-p k=-q
$$

where $q$ is an arbitrary positive constant. Let $V_{e}=\frac{1}{2} p e^{2}$, then using (30) and (32) we have: 


$$
\dot{V}_{e}=-\frac{1}{2} q e^{2}+p e\left[\left(\hat{f}\left(x / \underline{\theta}_{f}\right)-f(x)\right)+\left(\hat{g}\left(x / \underline{\theta}_{g}\right)-g(x)\right) u_{c}-d\right]
$$

then, we must have $\dot{V}_{e} \leq 0$ when $V_{e}$ is greater than a large constant $\tilde{V}$, however, from (33) we see that it is very difficult to design the $u_{c}$ such that the last term of (33) is less than zero. We solve this problem by appending another control term (supervisory control) $u_{s}$ to the $u_{c}$. So, the final control becomes

$$
u=u_{c}+u_{s}
$$

this additional control term is called a supervisory control. The purpose of this supervisory control $u_{s}$ is to force $\dot{V}_{e} \leq 0$ when $V_{e} \geq \widetilde{V}$. Substituting (34) into (11) and after some manipulations to force $\dot{V}_{e}$ to be negative, we obtain the following supervisory control:

$$
u_{s}=\left\{\begin{array}{l}
\operatorname{sgn}\left(\underline{e}^{T} P \underline{b}_{c}\right) \frac{1}{g_{L}(\underline{x})}\left[|\hat{f}|+f^{U}+\left|\hat{g} u_{c}\right|+\left|g^{U} u_{c}\right|+d_{m}\right] \\
\text { if } \quad V_{e} \geq \tilde{V} \\
0 \quad V_{e}<\tilde{V}
\end{array}\right.
$$

where $f^{U}(\underline{x})$ an upper bound of $f, g^{U}(\underline{x})$ and $g_{L}(\underline{x})$ are an upper and an lower bounds of $g$, respectively and $d_{m}$ is the upper bound of a perturbation $d$. Next, we replace $\hat{f}$ and $\hat{g}$ by the type-2 fuzzy logic systems given in (29) and (30). In order to adjust the parameters $\underline{\theta}_{f}$ and $\underline{\theta}_{g}$ in the type-2 fuzzy logic systems, we derive the following adaptive laws:

$$
\begin{aligned}
& \dot{\theta}_{f}=-\gamma_{1} e p \underline{\xi}_{f}(x) \\
& \dot{\theta}_{g}=-\gamma_{2} e p \underline{\xi}_{g}(x) u_{c}
\end{aligned}
$$

\section{SIMULATION RESULTS}

To prove the effectiveness of the developed controller, simulations on an IM have been carried out. The overall control system which has been simulated is shown in Figure 1. The three-phase induction motor is characterized by the parameters shown in Table 1 . The current-controlled inverter is fed by $514 \mathrm{~V} \mathrm{DC}$ voltages, and the hysteresis bandwidth of stator current is fixed to $0.1 \mathrm{~A}$. We admit that the influence of the flux on the dynamic of the speed is neglected. In this case, the bounds $f^{U}, g^{U}$ and $g_{L}$ for each controller are chosen in according with (9) and (10) as follows:

- Speed controller bounds:

$$
f^{u}=\frac{f}{J} N, g^{u}=1.1 g^{\prime}, \quad g_{L}=0.9 g^{\prime} \text { with } g^{\prime}=\frac{30 p L_{m} \phi_{r}^{r e f}}{\pi J L_{r}}
$$

- Flux controller bounds:

$$
f^{u}=1.1 \frac{\phi_{r}^{\text {est }}}{T_{r}}, \quad g^{u}=1.1 g^{\prime \prime}, \quad g_{L}=0.9 g^{\prime \prime} \text { with } g^{\prime \prime}=\frac{L_{m}}{T_{r}}
$$

The desired flux and speed tracking are involved with regulator coefficients tuned by trial and error to the values given in Table 2. The speed response and the speed reference $(1000 \mathrm{rpm})$ are depicted in Figure 4(a), which shows good performances in tracking and an excellent load charge rejection caused by the applied load torque shown in Figure 4(b). The corresponding electromagnetic torque response is generated, as shown in Figure 4(c), to compensate the load charge and to keep speed regulation, see also current of phase an in Figure 4(d). In Figures 4(e)-(f), it can be seen that the flux is well oriented along the d-axis of the synchronous frame and controlled to have a constant value. 
Table 1. Induction motor parameters

\begin{tabular}{|c|c|}
\hline & otor $1.5 \mathrm{~kW}, 2$ \\
\hline$\overline{R_{\mathrm{s}}}$ & $4.850 \Omega$ \\
\hline $\mathrm{R}_{\mathrm{r}}$ & $3.805 \Omega$ \\
\hline $\mathrm{L}_{\mathrm{s}}$ & $0.274 \mathrm{H}$ \\
\hline $\mathrm{L}_{\mathrm{r}}$ & $0.274 \mathrm{H}$ \\
\hline $\mathrm{L}_{\mathrm{m}}$ & $0.258 \mathrm{H}$ \\
\hline $\mathrm{J}$ & $0.031 \mathrm{Kg} \mathrm{m}^{2}$ \\
\hline B & $0.080 \mathrm{~N} \mathrm{~m} \mathrm{~s}$ \\
\hline$P$ & 2 \\
\hline
\end{tabular}

Table 2. Control coefficients

\begin{tabular}{lllllllll}
\hline & $\mathrm{q}$ & $\mathrm{k}$ & $\mathrm{p}$ & $\mathrm{M}_{\mathrm{f}}$ & $\mathrm{M}_{\mathrm{g}}$ & $\gamma_{\mathrm{f}}$ & $\gamma_{\mathrm{g}}$ & $\mathrm{V}_{\mathrm{t}}$ \\
\hline Flux controller & 10 & 80 & 0.00625 & 15 & 4 & 3.75 & 0.4 & 0.0001 \\
Speed controller & 10 & 50 & 0.1 & 400 & 640 & 4 & 6.4 & 0.1 \\
\hline
\end{tabular}

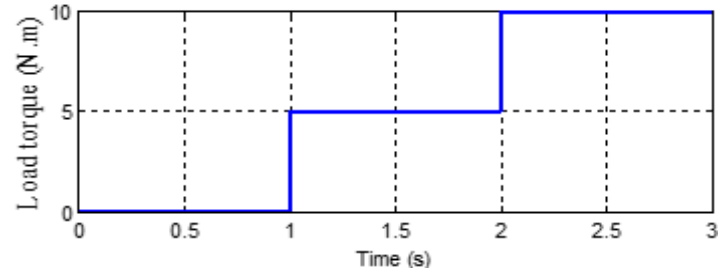

(a)

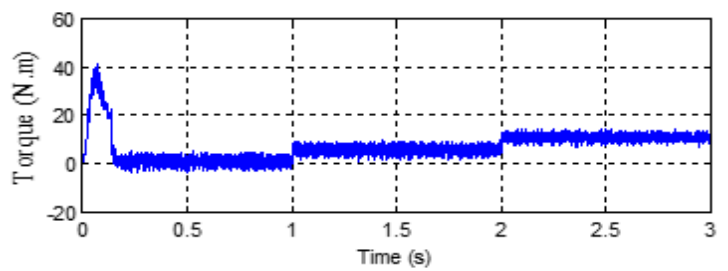

(c)

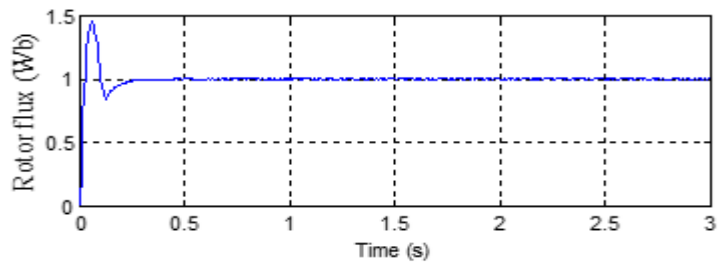

(e)

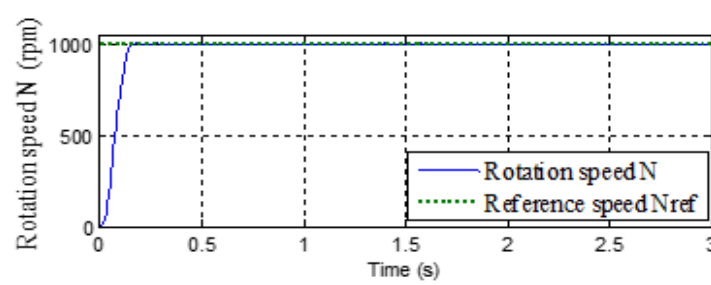

(b)

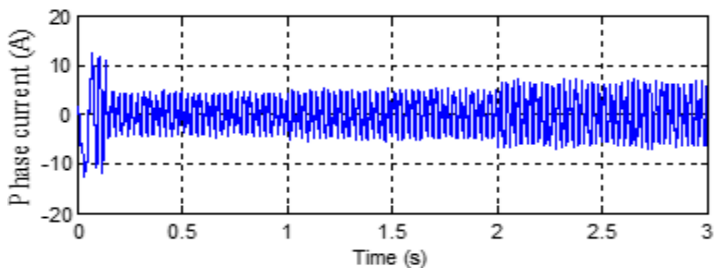

(d)

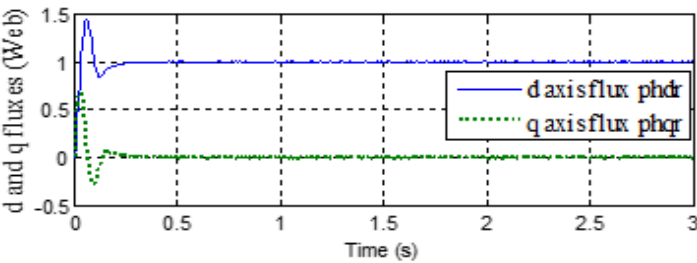

(f)

Figure 4. Flux-speed responses of induction motor, (a) Motor speed, (b) Applied load torque, (c) Electromagnetic torque, (d) Phase current, (e) Rotor flux, (f) d and q fluxes

In spite of these sudden changes, the controllers continue to work very well, where we see in Figures 5(a)-(b) the speed and flux tracking errors converge to zero in the steady states. It's clear from Figures 5(c)-(d) that the supervisory control actions of the two controllers were activated many times in order to stabilize the closed-loop system. Simulation results show that the speed and flux type-2 AFC yield excellent dynamic performances for an induction motor drive and they assure the insensitivity to the working conditions. In order to evaluate the insensitivity to the parameters variations of the proposed controller, we keep the same load torque shown in Figure 4(b) and at the same time.

We increase the rotor resistance values with $50 \%$ at time $1 \mathrm{sec}$ and $100 \%$ at time $2 \mathrm{sec}$ as shown in Figure 6(a). It is clearly shown from Figures 6(b)-(c) that the speed and its corresponding tracking errors converge to zero and stay small. Note also that fluxes responses are very satisfactory as shown in Figures 6(d)-(f). To evaluate the performances of our approach, we will compare it with two other techniques: an optimized PID controller and a type-1 version of the proposed method. The parameters of the PID controller $\left(K_{p}, K_{d}\right.$ and $\left.K_{i}\right)$ are optimized by particle swarm optimization (PSO) technique as explained in [24]. During optimization simulations, swarm populations are set to 20 particles and its coefficients $w, c_{1}$ and $c_{2}$ are set to $0.8,1$ and 1.5 , respectively [24]. 


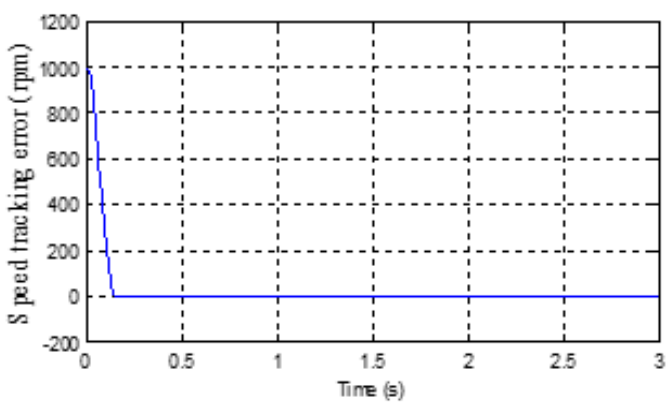

(a)

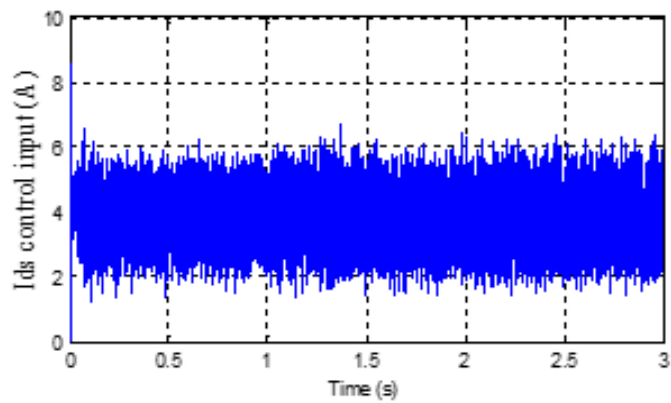

(c)

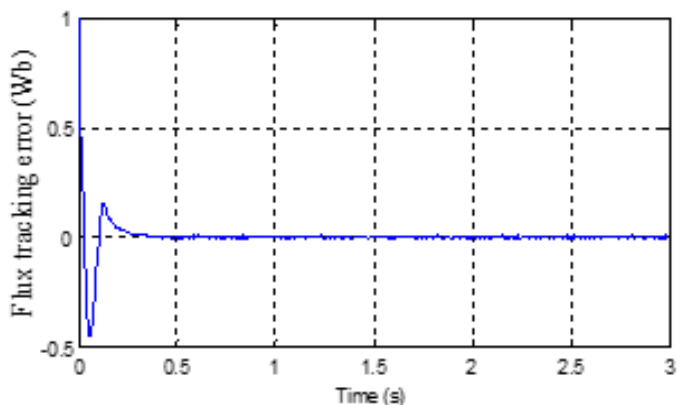

(b)

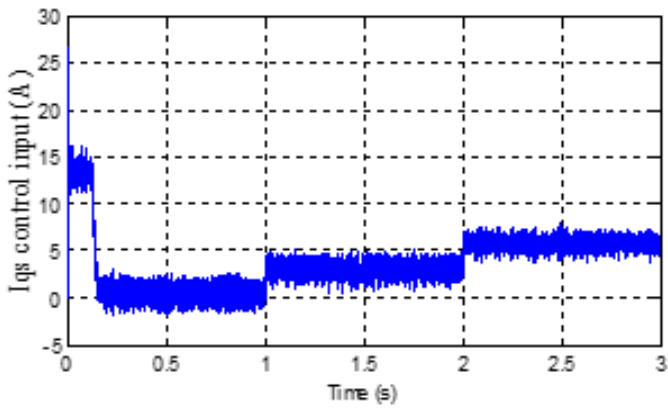

(d)

Figure 5. Flux-speed errors tracking and control actions, (a) Speed tracking error, (b) Flux tracking error, (c) s-current control input, (d) d-current control input

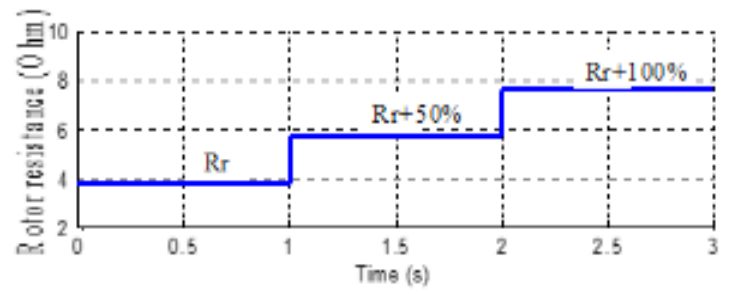

(a)

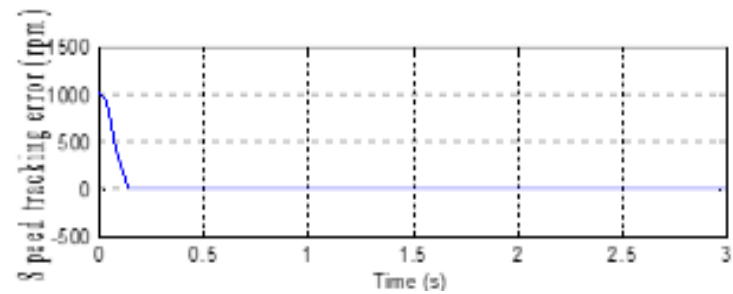

(c)

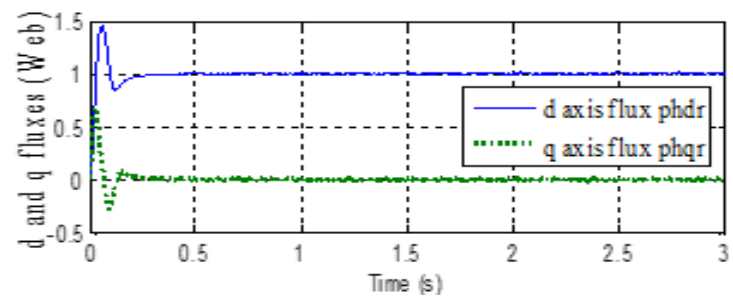

(e)

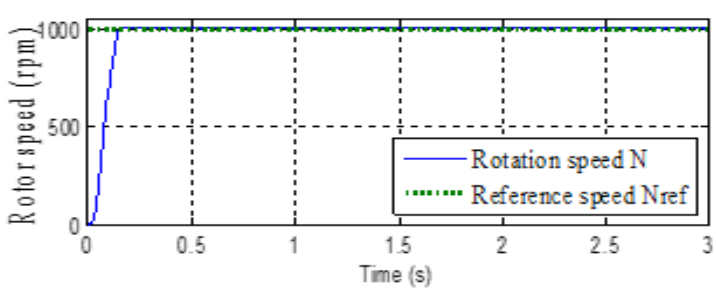

(b)

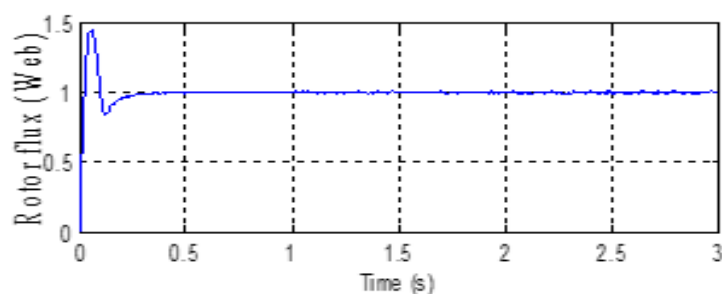

(d)

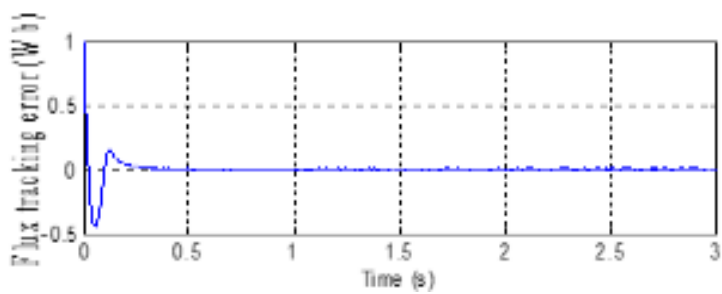

(f)

Figure 6. Robustness tests under parametric variations, (a) Rotor resistance variation, (b) Rotor speed, (c) Speed tracking error, (d) Rotor flux, (e) d and q fluxes, (f) Flux tracking error 
The type-1 version of our type-2 adaptive fuzzy controller is obtained just by eliminating the lower membership functions form the type- 2 membership functions represented in Figure 4 which gives us a type-1 membership functions, and then the type reducer bloc is eliminated as shown in Figure 2. Note that the presented type-2 fuzzy adaptive controller gives more accurate rotor speed compared to the PID and the type-1 fuzzy controllers as shown in Figure 7. For quantitative comparison purposes, the performance of the proposed method is evaluated by using the MSE (mean square error) criterion between the reference speed $N^{r e f}$ and the actual rotor speed $N$ as follows:

$$
\operatorname{MSE}(\text { speed })=\frac{1}{K} \sum_{i=1}^{K}\left(N-N^{\text {ref }}\right)^{2}
$$

We show in Table 3 the corresponding MSEs (speed) for the three controllers where we confirm the superiority with respect to precision of the proposed controller over the PID and type-1 fuzzy controller. To compare the amount of energy needed by the three controllers, let's define the MSE of the torque with respect to zero torque as follows:

$$
\operatorname{MSE}(\text { torque })=\frac{1}{K} \sum_{i=1}^{K}\left(T_{e}-0\right)^{2}=\frac{1}{K} \sum_{i=1}^{K} T_{e}^{2}
$$

The formula (41) can be used as a measure of the control effort. According to (41), we see in Table 3 that the motor torque reach its minimum values with our type-2 fuzzy controller, which is a proof that our proposed controller can achieve better performances (MSE speed) with minimum energy (MSE torque). To confirm more the efficiency of the proposed method, let's check it with a very big challenge which is the zero speed (low speed) tracking. In this case, a reference speed of $20 \mathrm{rpm}$ is applied, and the obtained results are depicted in Figure 8, where we clearly see the high performances of the type-2 fuzzy adaptive controller over its type-1 counterpart and the PID controller (very big ripples in the case of PID and type-1 fuzzy controllers but small ripples with the type-2 fuzzy controller). This fact is confirmed numerically in Table 4.

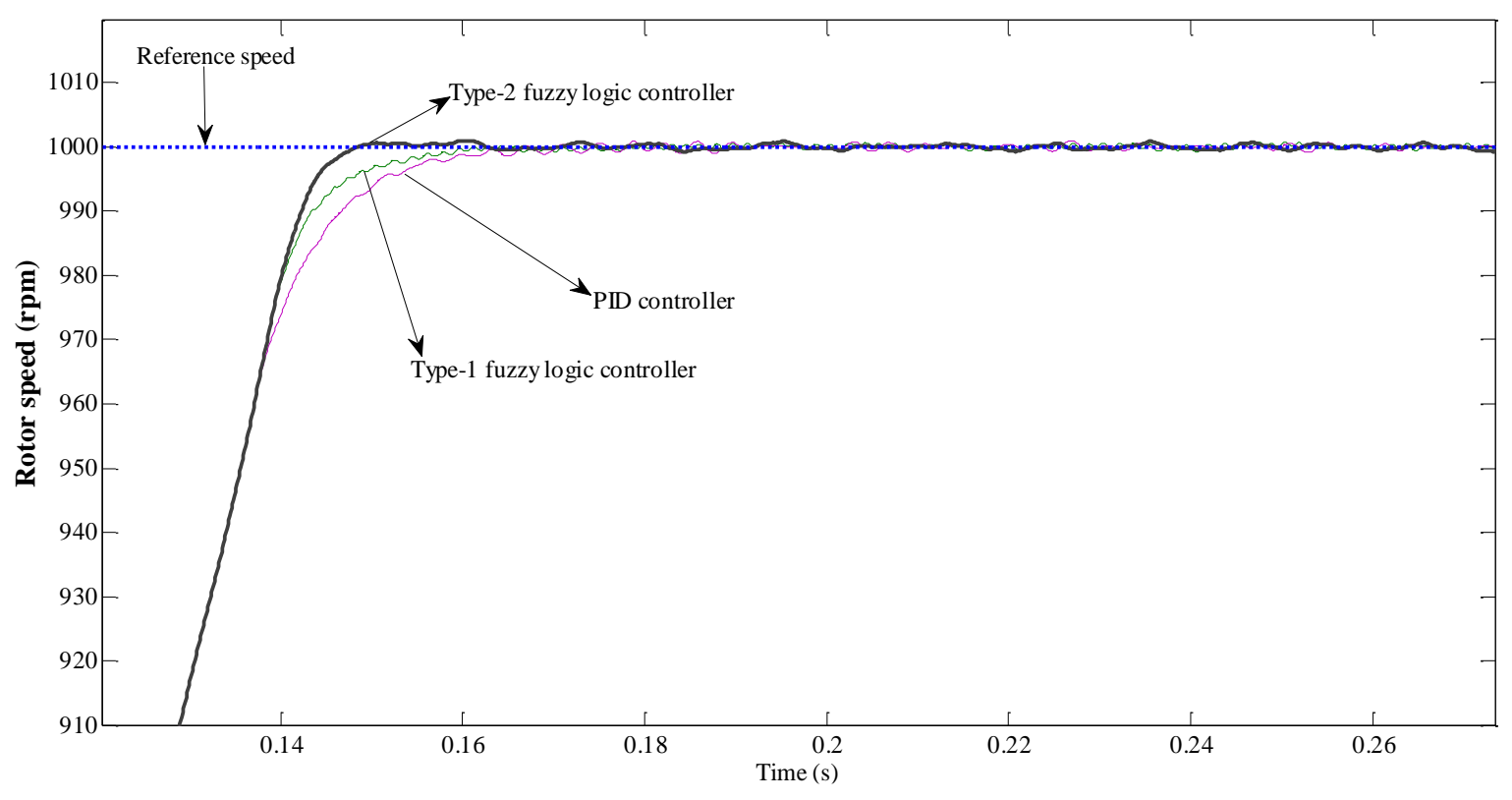

Figure 7. Superposition of the speed responses of PID, type-1 fuzzy and type-2 fuzzy controllers

Table 3. Comparative table

\begin{tabular}{llll}
\hline & \multicolumn{4}{c}{ PID } & Type-1 & Typ-2 \\
\hline MSE (Speed) & $6.7135^{*} 10^{6}$ & $2.6960 * 10^{6}$ & $8.3731 * 10^{5}$ \\
MSE (Torque) & $8.8842 * 10^{6}$ & $8.1005 * 10^{6}$ & $8.0135^{*} 10^{5}$ \\
\hline
\end{tabular}




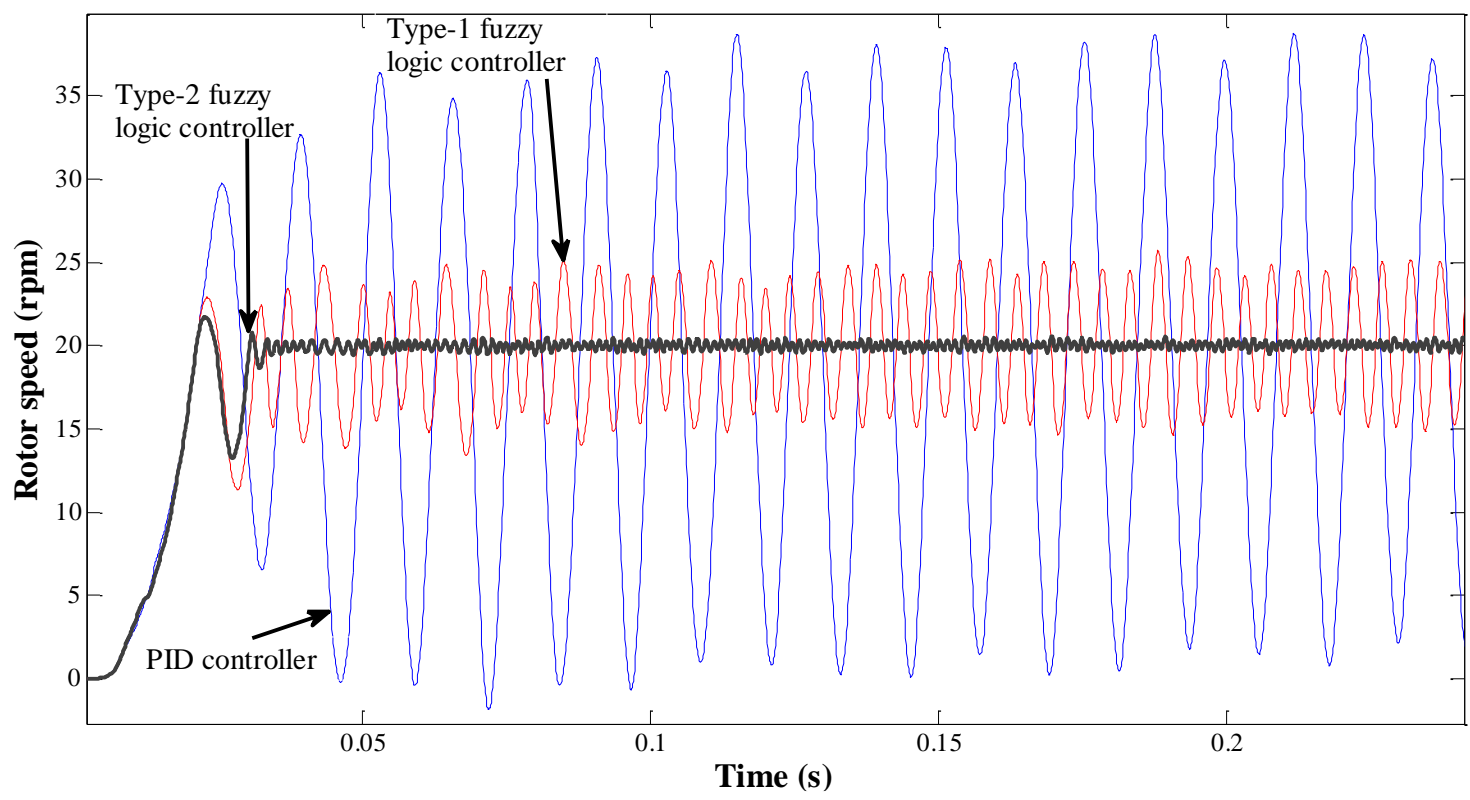

Figure 8. Superposition of the speed responses of PID, type-1 fuzzy and type-2 fuzzy controllers in low speed case

Table 4. Comparative table in low speed

\begin{tabular}{llll}
\hline & PID & Type-1 & Typ-2 \\
\hline MSE (low Speed) & $3.6215^{*} 10^{4}$ & $1.7925 * 10^{4}$ & $1.0466 * 10^{3}$ \\
\hline
\end{tabular}

\section{CONCLUSION}

In this investigation, an indirect adaptive fuzzy controller based on type-2 fuzzy systems with a supervisory controller has been designed and applied to the control of an induction motor drive. Based on Lyapunov synthesis approach, the free parameters of the type-2 fuzzy adaptive controller can be tuned on-line by an adaptive law. It has been shown that the proposed controller can provide the properties of insensitivity to uncertainties and external disturbances. Simulation results showed that our proposed approach is very effective to control an induction motor. The superiority of our algorithm over other techniques like PID control and type-1 fuzzy adaptive controller was confirmed by a short comparative study.

\section{REFERENCES}

[1] T. T. Nguyen, "The neural network-combined optimal control system of induction motor," International Journal of Electrical and Computer Engineering, vol. 9, no. 4, pp. 2513-2522, 2019.

[2] A. Agrawal, "Indirect vector control for induction motor drive using two level and five level inverter," International Journal of Applied Power Engineering, vol. 8, no. 2, pp. 134-144, 2019.

[3] Y-C. Kim, H-B. Song, M-T. Cho, and S-H. Moon, "A study on direct vector control system for induction motor speed control," Embedded and Multimedia Computing Technology and Service, vol. 181, pp. 599-612, 2012.

[4] N. T. García, Y. A. G. Gómez, and F. E. H. Velasco, "Parameter estimation of three-phase linear induction motor by a DSP-based electric-drives system," International Journal of Electrical and Computer Engineering, vol. 10, no. 1, pp. 626-636, 2020.

[5] F. Martinez, H. Montiel, and E. Jacinto, "Hybrid fuzzy-sliding grasp control for underactuated robotic hand," TELKOMNIKA Telecommunication Computing Electronics and Control, vol. 17, no. 4, pp. 2070-2075, 2019.

[6] A. Lokriti, I. Salhi, S. Doubabi, and Y. Zidani, "Induction motor speed drive improvement using fuzzy IP-self tuning controller, A real time implementation," ISA transactions, vol. 52, no. 3, pp. 406-417, 2013.

[7] K. Manickavasagam, "Fuzzy logic controller based single buck boost converter for solar PV cell," International Journal of Applied Power Engineering, vol. 3, no.1, pp. 1-8, 2014.

[8] S. Rafa, A. Larabi, L. Barazane, M. Manceur, N. Essounbouili, and A. Hamzaoui, "Implementation of new fuzzy vector control of induction motor," ISA transactions, vol. 53, pp. 744-754, 2014.

[9] S. M. Gadoue, D. Giaouris, and J. W. Finch, "MRAS sensorless vector control of an induction motor using new sliding-mode and fuzzy-logic adaptation mechanisms," in IEEE Transactions on Energy Conversion, vol. 25, no. 2, pp. 394-402, 2010.

[10] N. Bounar, A. Boulkroune, F. Boudjema, M. M'Saad, and M. Farza, "Adaptive fuzzy vector control for doubly-fed induction motor," Neurocomputing, vol. 151, pp. 756-769, 2015. 
[11] S. Allaoui, K. Chafaa, Y. Laamari, and B. Athamena, "Induction motor state estimation using tuned Extended Kalman Filter," 2015 4th International Conference on Electrical Engineering (ICEE), Boumerdes, 2015, pp. 1-5.

[12] N. N. Karnik, J. M. Mendel, and Qilian Liang, "Type-2 fuzzy logic systems," in IEEE Transactions on Fuzzy Systems, vol. 7, no. 6, pp. 643-658, 1999.

[13] K. Chafaa, L. Saidi, M. Ghanai, and K. Benmahammed, "Direct adaptive type-2 fuzzy control for nonlinear systems," International Journal of Computaional Intelligence and Applications, vol. 6, no. 3, pp. 389-411, 2006.

[14] K. Chafaa, L. Saidi, M. Ghanai, and K. Benmahammed, "Indirect adaptive interval type-2 fuzzy control for unknown nonlinear systems," Int. Journal of Modelling, Identification and Control, vol. 2, no. 2, pp. 106-119, 2007.

[15] S. M. Salaken, A. Khosravi, and S. Nahavandi, "Modification on enhanced Karnik-Mendel algorithm," Expert Systems with Applications, vol. 65, pp. 283-291, 2016.

[16] K. Tai, A. R. El-Sayed, M. Biglarbegian, C. I. Gonzalez, O. Castillo, and S. Mahmud, "Review of recent type-2 fuzzy controller applications," Algorithms, vol. 9, no. 2, pp. 1-19, 2016.

[17] D. Wu and J. M. Mendel, "Enhenced karnik-mendel algorithms," IEEE Transaction on Fuzzy Systems, vol. 17, no. 4, pp. 923-934, 2009

[18] M. Benbrahim, N. Essounbouli, A. Hamzaoui, and A. Betta, "Adaptive type-2 fuzzy sliding mode controller for SISO nonlinear systems subject to actuator faults," Int. J. of Automation and Computing, vol. 10, pp. 335-342, 2013.

[19] Xinwang Liu, Jerry M. Mendel, and Dongrui Wu, "Study on enhanced Karnik-mendel algorithms: Initialization explanations and computation improvements," Information sciences, vol. 184, no. 1, pp. 75-91, 2012.

[20] Li-Xin Wang, "Adaptive Fuzzy Systems and control: Design and stability Analysis," Prentice Hall, 1994.

[21] C-H. Wang, H-L. Liu, and T-C. Lin, "Direct adaptive fuzzy-neural control with state observer and supervisory controller for unknown nonlinear dynamical systems," in IEEE Trans. on Fuzzy Syst., vol. 10, no. 1, pp. 39-49, 2002.

[22] M. Hojati and S. Gazor, "Hybrid adaptive fuzzy identification and control of nonlinear systems," in IEEE Transactions on Fuzzy Systems, vol. 10, no. 2, pp. 198-210, 2002.

[23] A. Hamzaoui, N. Essounbouli, K. Benmahammed, and J. Zaytoon, "State observer based robust adaptive fuzzy controller for nonlinear uncertain and perturbed systems," in IEEE Transactions on Systems, Man, and Cybernetics, Part B (Cybernetics), vol. 34, no. 2, pp. 942-950, 2004.

[24] Y. Laamari, K. Chafaa, and B. Athamena, "Particle swarm optimization of an extended Kalman filter for speed and rotor flux estimation of an induction motor drive," Electrical engineering, vol. 97, pp. 129-138, 2015.

\section{BIOGRAPHIES OF AUTHORS}
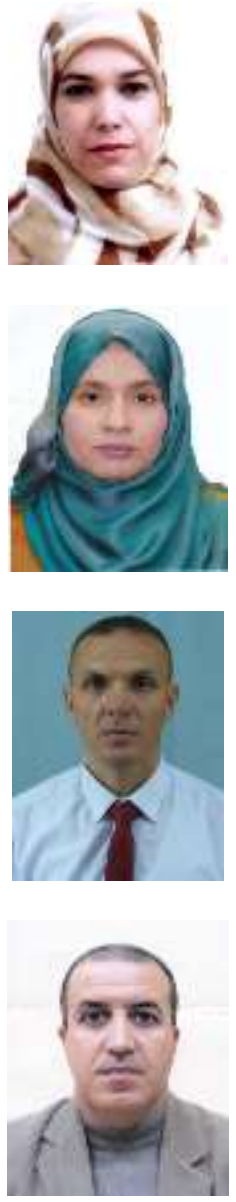

Nadia Bounouara was born in Batna, Algeria, in 1975. She received both of engineer degree in control and magister degree in robotic from Electronics Department, Batna 2 University, Algeria, in 2001 and 2011 respectively. She is currently a Ph.D student in robotics at Electronics Department, University of Batna 2; Algeria. Her research interests include nonlinear systems, Type-1 fuzzy control, metaheuristic optimization, robotics and observers.

Mouna Ghanai was born in Batna, Algeria, in 1975. She received the engineer degree in industrial control from Batna University, Algeria, in 1999, master degree in industrial control from Setif University, Algeria, in 2006 and the doctorate es-science grade in electronic from Batna University, Algeria, in 2013. Currently, she is an assistant professor at the Department of Electronics, Faculty of Technology, University Batna 2 Mostefa BenBoulaid, Batna, Algeria. Her research interests include modelling and identification of nonlinear systems, automatic control, and biomedical signal processing.

Ali Medjghou received the Bachelor degree in automatic, master degree in advanced automatic from Electrical Engineering Department, University of Biskra, Algeria and doctorate degree in robotics and artificial intelligence from Electronics Department, University of Batna 2 Mostefa BenBoulaid, Algeria. He is a member of the research team at Laboratory of Identification, Commande, Control and Communication (LI3CUB), University Mohamed Khider Biskra, Algeria. His research interests include robotic and artificial intelligence.

Kheireddine Chafaa was born in Batna, Algeria, in 1971. He received the engineer, magister and doctorate es-secience diplomas in industrial control from Batna University, Algeria, in 1994, 1999, and 2006 respectively. Currently, he is a professor at the Department of Electronics, Faculty of Technology, University Mostefa BenBoulaid, Batna 2, Algeria. His research interests include modeling and identification of nonlinear systems, nonlinear and adaptive control, soft computing, and biomedical signal processing. 